and Cellular Endocrinology

Elsevier Editorial System(tm) for Molecular

Manuscript Draft

Manuscript Number: MCE-D-16-00795R1

Title: Impact of G protein-coupled receptor heteromers in endocrine systems

Article Type: SI:GPCR signaling

Keywords: GPCR, dimer, oligomer, signaling, heteromer

Corresponding Author: Dr. Kim Jonas,

Corresponding Author's Institution: St Georges university of London

First Author: Kim Jonas

Order of Authors: Kim Jonas

Manuscript Region of Origin: UNITED KINGDOM

Abstract: The fine-tuning of endocrine homeostasis is regulated by dynamic receptor mediated processes. The superfamily of G protein-coupled receptors (GPCRs) have diverse roles in the modulation of all endocrine axes, thus understanding the mechanisms underpinning their functionality is paramount for treatment of endocrinopathies. Evidence over the last 20 years has highlighted homo and heteromerization as a key mode of mediating GPCR functional diversity. This review will discuss the concept of GPCR heteromerization and its relevance to endocrine function, detailing in vitro and in vivo evidence, and exploring current and potential pharmacological strategies for specific targeting of GPCR heteromers in endocrine heath and disease. 
Dr Kim Jonas

IMBE/MCS

St George's University

of London

Cranmer Terrace

London SW17 ORE

$5^{\text {th }}$ January 2017.

Dear Dr Hanyaloglu,

Re: MCE SI GPCR signalling article- revised article

We are pleased to resubmit our revised article and our responses to the reviewer's comments.

Yours sincerely

Dr Kim Jonas 
We thank the reviewer for their comments and suggestions. The specific comments have been addressed as follows:

1. Within the entire text, hetero-merisation has been changed to 'heteromerization'.

2. The suggested change has been made to 'prescription drugs targeting' to the introduction, line 4.

3. All in vitro, in vivo and ex vivo have been italicised throughout the manuscript.

4. The repeated 'such as' in Section 2, page 4, paragraph 1, line 6, has been removed.

5. The US spelling of localization has been used and corrected throughout the manuscript.

6. Two references have been inserted into page 4, paragraph 2- Gomes et al, 2016; Kenakin et al, 2010.

7. On page 5, GB1-and GB2 have been edited to the full versions of GABAB1 and GABAB2 respectively.

8. On page 5, paragraph 1, 'One common for regulation within a heteromer..' has been changed to 'One common mode of regulation...'.

9. On page 5 , point 3, b-arrestin has been changed to $\beta$-arrestin.

10. Co-localising has been changed to co-localizing, and also checked and changed throughout the entire manuscript.

11. On page 6, paragraph 1, the sentence "The functional significance of the GHSR/MC3R heteromers in vitro' has been changed to 'The functional significance of the GHSR/MC3R heteromers, examined in vitro...'.

12. On page 6 , paragraph $2, T$. Schwartz has been removed from the references bracket.

13. References by Jonas et al 2014 and Peltoketo et al 2010 have been added to page 7. Section 3.2. and Huhtaniemi review deleted.

14. On page 7 , paragraph 2 , heteromerise has been changed to heteromerize, and corrected throughout the manuscript.

15. On page 7, paragraph 2; the word 'receptors' has been removed from the sentence 'of the LHR and FSHR receptors'.

16. On page 9, paragraph 1. The 'set point' is referring to the sensing of glucose levels and resulting modulation of insulin secretion via heteromer formation and activity. To clarify this, the sentence has been changed to 'Thus, suggesting a role for the GSHR/SST5a heteromer formation and activity in fine-tuning and regulating $\beta$ isletcell mediated insulin secretion'.

17. On page 9, paragraph 3; 'B2 has been changed to 'B2R'.

18. On page 9, paragraph 4, 'Heteromerization can provide a mechanism underlying how the multifaceted functional roles of a single receptor subtype can be mediated, providing novel pharmacological and signalling responses via heteromer formation' has been changed to 'Heteromerization can provide a mechanism underlying how the multifaceted functional roles of a single receptor subtype can be mediated.'.

19. On page 10, paragraph 1, the sentence has been re-written to 'The main strategies to target GPCR heteromers to date are to activate the heteromer specifically via bivalent ligands, using small molecules that target heteromer-specific allosteric 
binding pockets, or inhibit heteromer function via a drug combination approach, or multifunctional ligands.

20. On page 10, paragraph 2 , the sentence has been changed to 'Interestingly this compound is a biased ligand to the $\beta$-arrestin pathway for these heteromers'.

21. On page 10, paragraph 2. Gomes et al, 2013, has been added to the end of the paragraph.

22. On page 11, the statement 'intra-GPCR family' has been removed.

23. On page 11, Section 5.2, the reference by Ayoub et al 2015, has been added to this section.

24. The entire document has been checked, and all 'signalling' have been changed to the U.S. spelling of 'signaling'.

25. The following references have been added into the statements on page 13:

- crystal structures of homodimers (Geng et al, 2016; Fotiadis et al, 2006) and homo-oligomers (Huang et al 2013) have been identified'

- ' 'use of nanobodies in GPCR research' Maio and McCammon 2016; Staus et al, 2016; DeVree et al, 2016; Ring et al, 2013; Maussang et al, 2013; Nygaard et al, 2013; Irannejad et al, 2013; Rasmussen et al, 2011). 


\title{
Impact of G protein-coupled receptor heteromers in endocrine systems
}

K.C. Jonas ${ }^{1 *}$ and A.C Hanyaloglu²,

1. Cell Biology and Genetics Research Centre and Centre for Medical and Biomedical Education, St George's, University of London, UK

2. Institute of Reproductive and Developmental Biology, Dept. Surgery and Cancer, Imperial College London, UK

*Corresponding Author: Dr Kim Jonas, Email: kjonas@sgul.ac.uk

Keywords: GPCR, dimer, oligomer, signaling, heteromer.

\begin{abstract}
Abbreviations:
$\alpha 1 \mathrm{~B}$ adrenergic receptors ( $\alpha 1 \mathrm{BR})$; Angiotensin 1 receptor (AT1R); Bioluminescence resonance energy transfer (BRET); Bradykinin 2 receptor (B2R); Corticotrophin releasing hormone $(\mathrm{CRH})$; Dopamine D2 receptor (D2R); Fluorescence resonance energy transfer (FRET); Follicle stimulating hormone receptor (FSHR); Gastricinhibitory polypeptide receptors (GIPR); Glucagon-like peptide-1 (GLP-1); G proteincoupled receptor (GPCR); Growth hormone secretagogue receptor (GHSR); Luteinizing hormone receptor (LHR); $\mu$-opioid receptor $(\mu \mathrm{OR})$; Melanocortin-3 receptor (MC3R); Proximity ligation assay (PLA); Vasopressin $1 \mathrm{~b}$ receptor (V1bR)
\end{abstract}




\section{Abstract}

The fine-tuning of endocrine homeostasis is regulated by dynamic receptor mediated processes. The superfamily of G protein-coupled receptors (GPCRs) have diverse roles in the modulation of all endocrine axes, thus understanding the mechanisms underpinning their functionality is paramount for treatment of endocrinopathies. Evidence over the last 20 years has highlighted homo and heteromerization as a key mode of mediating GPCR functional diversity. This review will discuss the concept of GPCR heteromerization and its relevance to endocrine function, detailing in vitro and in vivo evidence, and exploring current and potential pharmacological strategies for specific targeting of GPCR heteromers in endocrine heath and disease. 


\section{Introduction}

G protein-coupled receptors (GPCRs) are pervasive to most physiological and endocrinological processes. Their necessity in maintaining endocrine homeostasis makes them a lucrative therapeutic target, with approximately $40 \%$ of current prescription drugs targeting a GPCR. Resulting pathophysiological disorders caused by GPCR dysfunction drives our need to dissect the basic science underpinning the complex modalities of GPCR regulation. Furthermore, understanding these processes is paramount to more targeted and efficacious next generation pharmaceuticals and to personalized medicine approaches (1).

Homo/heteromerization of GPCR is now a widely accepted modality of how GPCRs regulate their physiological functions $(1,2)$. The current evolved model of GPCR signaling incorporates the ever-increasing complexity in GPCR signal pathways and mechanisms of regulation, to which homo/heteromerization has made a significant contribution. Although most studies have documented homo/heteromerization using heterologous cell lines, several studies have demonstrated the in vivo significance of these receptor-receptor interactions. Such complexity in receptor regulation provides key mechanism/s for the multiple and dynamic roles these receptors play in vivo.

This review will discuss the functional and in vivo evidence for GPCR heteromers in endocrine systems. We will describe the criteria for assessing and classifying GPCR heteromers, review their known functional impact from both in vitro and in vivo studies of these hetero-complexes on endocrine function.

\section{Detecting and classifying GPCR heteromers-an overview}

GPCR heteromerization is defined as a macromolecule complex composed of at least two receptor units, with biochemical properties that are demonstrably different from those of its individual components (2). With an increase in the number of reports identifying GPCR heteromers, the resulting challenges in distinguishing the difference between receptors localised to the same cell undergoing functional crosstalk, versus receptors complexed as physiologically relevant heteromers became an important distinction. Thus, three consensus criteria were published by the International Union of Basic and Clinical Pharmacology to facilitate the classification of true GPCR heteromers (3). The first of these criteria concerns the requirement for 
evidence of physical receptor-receptor interactions in native or primary tissue. Traditionally, methods such as co-immunoprecipitation and resonance energy transfer techniques (4-8) have been used to demonstrate receptor-receptor interactions and hence the proximal existence of heteromers. Recent technological advances in super-resolution and single molecule imaging present an innovative methodology for detecting GPCR heteromers. Techniques such as fluorescent correlation spectroscopy $(9,10)$, single particle tracking via total internal-reflection fluorescent microscopy (11-13) and localization microscopy techniques such as photoactivated localization microscopy $(14,15)$ have been utilised to identify GPCR heteromers and homomers. Likewise, proximity ligation assays (PLA), also provide a mechanism for identifying heteromers in native tissues (16).

The second consensus criteria requires there to be heteromer-specific properties, be it a change in the pharmacology of the receptors via $G$ protein specificity or allosteric binding properties, or ligands that are heteromer-specific. This is demonstrated via classical biochemical, pharmacological and cell signaling techniques to determine changes in ligand binding, G protein-dependent and $G$ protein-independent signal activation. The third criteria necessitates the requirement for the direct physiological evidence for the importance of the identified heteromer. Methodology used to determine this include RNA interference or in vivo studies to introduce genetic modifications in receptor protomers participating in the heteromer. If the transmembrane interface is known, expression or incubation of cell permeable peptides corresponding to the transmembrane region have been employed in vitro and in vivo. Thus, confirming the physiological requirement for the heteromer $(2,3)$.

In practice, there are very few identified heteromers that fit all three criteria; with criteria three often the hardest to fulfil given that most functional heteromers have been identified using heterologous cell lines. Therefore, fulfilment of two out of three of the criteria are required for the acceptance of a GPCR heteromer. With respect to endocrine systems, most identified GPCR heteromers that fulfil all three inclusion criteria are neuroendocrine in nature. The functional significance of which will be discussed in further detail.

\section{Impact of GPCR heteromers on receptor activity in endocrine systems}

The canonical view of GPCR signaling has evolved from a ligand binding to a single monomeric receptor that activates a single heterotrimeric $G$ protein, to one of 
growing complexity. GPCR homo/heteromerization provides a modality whereby receptors can mediate multiple functions via modulating receptor trafficking (both exo- and endocytosis), ligand specificity and functional selectivity. In obligatory heteromers such as the GABAB1 and GABAB2 receptors, (also observed with the sweet and umami taste receptors (17-19)), the functional significance of heteromerization is required for cell surface expression of both receptors, as well as G protein-coupling (20-22), via transactivation of GABAB1-GABAB2 heteromers. However, identifying the functional significance of GPCR heteromers are not always essential to all functions mediated by a specific receptor. That said, heteromer formation can increase the spectrum of ligand recognition and signal outcomes of a receptor. One common mode of regulation within a heteromer is via allosterism, the outcome of which can lead to distinct functional responses to that of the individual receptors. Broadly speaking, allosteric interactions within heteromers can lead to three different functional outcomes:

1. Ligand binding. Ligand binding within a heteromer results in either positive or negative cooperativity exerted on the neighbouring receptor(s) within the heteromer.

2. G protein recruitment. G protein selectivity may change or exert differential preferences between heteromeric and homomeric complexes.

3. G-protein independent mechanisms via $\beta$-arrestin recruitment. The heteromer may favour or acquire $G$ protein-independent functionality via $\beta$-arrestin recruitment.

Many GPCR heteromers have been shown to have direct roles in endocrine homeostasis, impacting metabolism, reproduction, nutritional status and stress responses (Table 1). The functional significance of such heteromers has largely been dissected using heterologous cell lines, examples of which will be discussed below.

\subsection{Metabolism and nutrition}

Endocrine-mediated feedback for the control of satiety and appetite is essential for maintaining metabolic homeostasis. Key pathways that regulate appetite stimulation and feeding are mediated via the growth hormone secretagogue receptor (GHSR). GHSR is expressed within various hypothalamic nuclei involved in food intake and reward-seeking behaviour (reviewed by (23)), and thus has been suggested to be a central player in regulating metabolic homeostasis in both a ligand-dependent (via 
Ghrelin) and -independent manner, via intrinsic basal GSHR activity $(23,24)$. Several studies have demonstrated GHSR to heteromerize with other GPCRs that also regulate metabolic status (23). Indeed, heteromerization of GSHR and the melanocortin-3 receptor (MC3R) was identified by fluorescence resonance energy transfer (FRET) (25), with immunohistochemical and in situ studies co-localizing GHSR and MC3R to the arcuate nucleus of the hypothalamus. The functional significance of the GHSR/MC3R heteromers examined in vitro via co-expression of GHSR and MC3R in COS-7 and HEK293 cells, showed that GSHR/MC3R heteromers may enhance MC3R-dependent cAMP accumulation yet decrease basal and ligand-induced GHSR activity. Moreover, the enhanced MC3R activity observed was dependent on the decrease in basal GHSR activity, suggesting positive and negative allosteric regulation between MC3R and GHSR protomers to create functionally asymmetric complexes (26).

Heteromers of the Class B GPCR family have been suggested to have roles in glucose homeostasis. Ligand-dependent BRET screening of the glucagon receptor family heteromeric and homomeric interactions in HEK293 cells, showed glucagonlike peptide-1 (GLP-1)-dependent heteromer formation between GLP1 and gastricinhibitory polypeptide receptors (GIPR). This heteromeric association was GLP-1specific, with reversal of GLP-1/GIPR association observed with titration of GIPR. Functionally, a change in the activity of the GLP-1R was also observed in terms of calcium response, and $\beta$-arrestin recruitment (27). There has also been recent evidence for functional cross-talk between $\mathrm{G} \alpha \mathrm{s}$ and $\mathrm{G} \alpha \mathrm{q}$-coupled receptors in the regulation of long chain fatty acid mediated incretin secretion. Recent findings have shown that GPR40-mediated GLP-1 release by colonic enteroendocrine cells requires high cAMP levels, achieved via the bile acid receptor TGR5 or GPR119dependent $\mathrm{G} \alpha \mathrm{s}$ activity $(28,29)$. Although these studies suggest functional cross talk at the level of G-protein dependent signaling between Gaq- and Gas-coupled GPCRs, whether this is mediated via heteromerization remains to be demonstrated.

Heteromers of vasopressin $1 \mathrm{~b}$ receptor $(\mathrm{V} 1 \mathrm{bR})$ and corticotrophin releasing hormone receptors $(\mathrm{CRHR})$ have also been demonstrated to be functionally important for mediating the biological functions of their respective hormones. In HEK293 cells, $\mathrm{V} 1 \mathrm{bR} / \mathrm{CRHR}$ heteromers were shown to act to synergistically enhance the G protein- 
dependent signal responses. Such enhancement of vasopressin and $\mathrm{CRH}$ function could underpin their importance in mediating metabolic responses via adrenocorticotrophin hormone release and insulin secretion (30).

\subsection{Reproduction}

The gonadotropin receptors follicle-stimulating hormone receptor (FSHR) and luteinizing hormone receptor (LHR) are essential for reproduction $(31,32)$. Expressed in specialised cellular compartments of the testis and ovary, FSHR and LHR coordinate gonadal steroidogenesis and the production and/or maturation of germ cells $(31,32)$. Both FSHR and LHR have been shown to form homomers in vitro $(15$, 33-38). Moreover, using a functional complementation approach, we have shown that transgenic co-expression of ligand-binding deficient LHR and signal deficient LHR could rescue the infertile phenotype of LHR knockout males (33), thus demonstrating that homomerization is a physiologically relevant mode of LHR function. Recent studies have also shown that the FSHR and LHR can heteromerize $(39,40)$. Heteromerization has been demonstrated using BRET $(40)$ and fluorescent correlation spectroscopy (39), moreover, heteromerization appears to alter the pharmacology of the LHR and FSHR by enhancing ligand disassociation, and negatively regulating cAMP production (40). LHR/FSHR heteromerization is only physiologically relevant to female reproduction, where co-expression of FSHR and LHR in granulosa cells primarily occurs during the peri-ovulatory period, (41). A defined window of co-expression suggests a role for the heteromer in modulating the pleurotrophic actions of LHR during ovulation. Recent studies have also found that co-treatment of FSH with either hCG or LH can potentiate their respective effects on steroidogenesis and apoptosis (42). Integration of these findings into the physiological role of LHR and FSHR remains to be demonstrated.

\section{In vivo role of GPCR heteromerization to health and disease}

Although many GPCR heteromers have been identified, the in vivo physiological role(s) of many remains speculative and inferred from heterologous cell types or primary cell cultures. This is mainly due to the technical difficulties often encountered with identifying endogenous receptors. However, with recent methodological advances, such as proximity ligation assays and time-resolved FRET, several 
studies have made significant head-way in identifying GPCR heteromers in vivo, and deciphering their functional roles.

Recent work has identified two novel heteromers of dopamine D4 receptor $(\mathrm{D} 4 \mathrm{R}) / \alpha 1 \mathrm{~B}$ adrenergic receptors $(\alpha 1 \mathrm{BR})$ and dopamine $\mathrm{D} 4 / \beta 1$ adrenergic receptors $(\beta 1 \mathrm{R})$, the formation of which is controlled by circadian rhythm and the light-dark cycle. A study by Gonzalez et al, identified D4R- $\alpha 1 B R$ and D4R- $\beta 1 R$ heteromers in primary pinealocytes and pineal glands, via proximity ligation assay (43), and that formation of D4R-adrenergic receptor heteromers was controlled by the expression level of D4R, with increased heteromer formation at sunrise, and decreased/little heteromer formation at sunset. Pharmacologically, adrenergic receptor-D4R heteromers cross-antagonised the release of melatonin via the regulation of the synthesis and secretion of serotonin, the precursor of melatonin. Thus, low level heteromer formation correlated with increased release of melatonin at sunset, and low melatonin release and high heteromer formation at sunrise (43), clearly exhibiting how key physiological functions are intricately controlled at the level of heteromer formation.

Isoforms of the dopamine receptor family have been shown to heteromerize with GHSR. Via TR-FRET and FRET, dopamine D2 receptor (D2R)/GHSR heteromers were demonstrated in vivo within the hypothalamus (44). Moreover, D2R/GHSR heteromers amplified the anorexigenic effects of D2R. Using cabergoline, the D2Rselective agonist, a dose-dependent suppression of food intake in wild-type and ghrelin knock-out mice was observed, however, there was no effect on food intake in GHSR knock-out mice. These data illustrate that the anorexigenic effects of D2R are augmented by GHSR, presenting a possible avenue for therapeutic interventions in food intake disorders (44).

GSHR and somatostatin $5 \mathrm{a}$ (SST5a) receptors have been demonstrated via TRFRET in $\beta$ islet cells of the pancreas. Heteromerization of GHSR and SST5a changed the G protein-coupling preference of GSHR to Gai, mediating ghrelin and somatostatin-induced inhibition of glucose-stimulated insulin secretion. Moreover, the degree of heteromerization detected was ligand-regulated, with high ghrelin and low 
somatostatin increasing heteromer formation, as detected via BRET (45). This, in turn regulated the canonical (GHSR- Gaq coupling) versus non-canonical (GHSRGai coupling) signaling detected. Thus, suggesting a role for the GSHR/SST5a heteromer formation and activity in fine-tuning and regulating $\beta$ islet-cell mediated insulin secretion (45).

A further study has also elucidated the in vivo roles of GHSR/GPR83 heteromers. GPR83 is an orphan GPCR expressed within hypothalamic nuclei where it controls energy balance, and co-localizes with GHSR in the arcuate nucleus. In vitro analysis using HEK293 cells demonstrated heteromerization of GPR83 and GHSR via BRET (46). Moreover, in vivo exploration of the physiological role of the GPR83/GHSR heteromers using transgenic knock-out approaches showed that GPR83 knockout mice were protected from weight gain when fed on high-fat diets, despite hyperphagia (46) demonstrating an intriguing role for GPR83 and GHSR heteromers in both feeding behaviour and energy metabolism.

In recent years, several heteromers have been identified with relevance to fetal/maternal health. The intriguing formation of angiotensin 1 receptor (AT1R) and bradykinin 2 receptor (B2R) heteromers were implicated in the pathophysiological development of pre-eclampsia $(47,48)$. The expression of AT1R-B2R heteromers were more abundant on platelets and omental vessels isolated from women with preeclampsia, with increased heteromer formation due to the upregulated expression of $\mathrm{B} 2 \mathrm{R}$, resulting in the elevation of angiotensin II-dependent Gaq activity.

'Heteromerization can provide a mechanism underlying how the multifaceted functional roles of a single receptor subtype can be mediated. Thus, the identification of GPCR heteromers in vitro, and the functional and physiological validation of heteromers in vivo identifies potential novel therapeutic interventions and drug targets.

\section{Pharmacological exploitation of GPCR heteromers}

GPCR heteromers have attracted significant attention from the pharmaceutical industry due to their potential to address the non-specific effects of drugs thought to 
result from heteromerization, or to exploit the novel properties of heteromers in the design of new therapeutics. The unique biochemical signature of GPCR heteromers, be it a change in trafficking, pharmacology or signaling properties, provide a platform for screening and differential drug targeting. Indeed, well-characterized GPCR heteromers have already been targeted in the development for novel treatment of Parkinson's disease, addiction, schizophrenia, depression and chronic kidney disease. (49). 'The main strategies to target GPCR heteromers to date are to activate the heteromer specifically via bivalent ligands, using small molecules that target heteromer-specific allosteric binding pockets, or inhibit heteromer function via a drug combination approach, or multifunctional ligands.

\subsection{Specific activation of GPCR heteromers}

Drug development strategies to specifically target GPCR heteromers focus on conditions where targeting of the heteromer has beneficial activities over the homomer. To date there are few known ligands with proven heteromer-specific activity in vivo. The best described examples are those targeting the opioid receptors. For example, CYM51010 is a repurposed compound thought to be a specific ligand for the $\mu-\delta$ opioid receptor heteromer (50). Interestingly this compound is a biased ligand to the $\beta$-arrestin pathway for these heteromers and activates analgesic responses similarly to morphine, yet with reduced tolerance under chronic treatment. The binding site of this compound may be an allosteric site unique to the heteromer, or at least distinct from each orthosteric site in each protomer, as the $\mu$-opioid receptor antagonist only partially inhibits the in vitro activity of the heteromer. Furthermore, the in vivo action of CYM51010 (but not morphine), was blocked by a heteromer-specific antibody, showing specificity for the heteromerspecific actions (50).

Bivalent ligands, in the context of GPCR homo/heteromerization, consist of a compound that is selective for one protomer linked by a spacer arm to a compound selective for its partner protomer. These are distinct from bitopic ligands that are compounds able to interact with orthosteric and allosteric sites. Although bitopic (or dualsteric) ligands have been designed based on a monomeric GPCR model, it is certainly possible that these ligands could be designed to be heteromer-specific, although this has not yet been explored for this class of compounds. Bivalent ligands 
are thought to target and stabilize pre-formed/constitutive heteromers rather than induce heteromerization (51) and have been used as tools to understand the functional significance of specific GPCR heteromers. To date many have been developed towards heteromers containing the $\mu \mathrm{OR}$. One interesting example is a bivalent ligand that targets the heteromer of $\mu \mathrm{OR} /$ metabotropic glutamate receptor 5 for treatment of chronic inflammatory pain. The compound identified was a $\mu O R$ agonist coupled to a metabotropic glutamate receptor 5 antagonist and also illustrated that highly defined spacer lengths were key to its activity in vivo (52). In the context of endocrine systems, bivalent ligands have provided a useful tool to support the clinical and therapeutic relevance of the D2R dopamine receptor/ somatostatin SST2 receptors in acromegaly. These heteromers are expressed in GH-secreting pituitary tumors and have enhanced Gai-signaling activity over their homomeric counterparts $(53,54)$. Employment of bivalent ligands, however, demonstrated that targeting both these receptors can effectively inhibit $\mathrm{GH}$ and prolactin secretion from $\mathrm{GH}$-secreting pituitary adenomas, more effectively than their response to somatostatin receptor antagonist octreotide $(55,56)$. Bivalent ligands have also been developed for the gonadotrophin hormone receptors in order to improve receptor specificity of allosteric low molecular weight compounds to these receptors. Although the study did not assess the compound in the context of LHR/FSHR heterodimers, a small molecular activator of both LHR and FSHR was made more specific to LHR (although resulted in a loss of potency) by linking it with an FSHR-specific negative allosteric modulator $(57,58)$

\subsection{Specific pharmacological inhibition of GPCR heteromer function}

GPCR heteromers may play a role in the off-target effect of certain drugs and/or have a demonstrated role in human disease, thus selective inhibition of these complexes has been achieved via combination therapy or bi/multifunctional ligands. A combination therapy approach relevant for endocrine systems is currently in Phase 2 clinical studies for chronic kidney disease. This is based on a therapy to target chemokine receptor CCR2/ angiotensin II type 1A receptor heteromers, repurposing two known antagonists for CCR2 and angiotensin 1A receptor, termed DMX-200 (59). 
Bifunctional or multifunctional peptide ligands could represent an alternate strategy to block action of specific heteromers. These peptide ligands possess agonist activity to one GPCR and antagonistic properties to another. For example, bifunctional ligands that are agonistic at $\delta$ and/or $\mu$-opioid receptors yet antagonistic at pro-nociceptive cholecystokinin receptor (60) or substance $P$ neurokinin-1 receptor (61), are thought to create a potent analgesic with fewer side effects than morphine (62), however it is unknown whether such compounds target heteromers of these receptors.

\section{Perspectives}

How individual cells integrate and decode multiple signals from an array of distinct receptors remains an outstanding question. The evidence to date strongly supports a significant role for GPCR heteromerization in the cellular signaling network, and the downstream significance of these associations in both health and disease. The number of reports of GPCR heteromers across diverse physiological and pathophysiological systems has dramatically increased, particularly as the technology to identify and characterise these heteromers- from the single molecule to its in vivo function- have been developed. Although this field of GPCR biology has driven continuous debate on the significance of such interactions, the communication of a standardized framework to study GPCR heteromers $(2,63)$ and tools to demonstrate in vivo significance will contribute to our evolving models of GPCR signaling.

Current challenges are to understand how to effectively exploit this complexity, although certain strategies are showing real promise, as discussed above. Furthermore, what is the extent of GPCR heteromerization and how does it contribute to the overall signal crosstalk in cells that express hundreds of distinct GPCRs exposed to multiple ligands? This latter question highlights a functional requirement for crosstalk via heteromerization of GPCRs that contain more than two GPCRs, considering not only oligomeric composition, but also that a heteromer may contain more than two different GPCRs. There is increasing evidence that for certain GPCRs heterotetramers may be the functional form, e.g. D2R-A2A and D2-D3 dopamine receptors, containing equivalent ratios of each GPCR, i.e. association of two homodimers (64). This is thought to provide a platform for coupling of distinct $G$ proteins, and certainly this is consistent with the idea that functionally asymmetric GPCR oligomers could regulate G protein signal strength (15). The idea that more 
than two GPCRs form heteromers has been demonstrated for chemokine receptors (heteromer of CCR2-CCR5-CXCR4) (65). Such complex associations could be highly significant for endocrine systems where extensive signal crosstalk is exposed to a highly dynamic extracellular environment. Despite the recent technical advances, a missing piece of the GPCR signaling puzzle is crystal structure information of a heteromeric GPCR complex. The explosion of available crystal structures of GPCRs has transformed drug design strategies for the GPCR monomer model, and although crystal structures of homodimers (66-67) and homo-oligomers (68) have been identified, heteromeric structures would provide unprecedented information, not only on interfaces, but unique heteromer-specific targeting sites for structure-based drug discovery. With the generation of antibodies that target GPCR heteromers and the use of nanobodies in GPCR research (69-76), there is a real technical possibility of creating tools to aid stabilisation of such structures for crystallization. Likewise there is increase interested in immunotherapy pathways, particularly in cancer, and whilst there are no current approved GPCR antibody drugs, antibodies specific to GPCR heteromers have been generated (77).

Overall, GPCR heteromers are becoming increasingly accepted as part of the GPCR signalosome, which is integrated in to an even more complex cellular network. As the signal wires mediated by GPCR heteromers are untangled, this will provide new insights and therapeutic avenues in to the roles of these GPCR complexes in endocrine systems.

\section{Acknowledgements}

This work was supported by Biotechnology and Biological Sciences Research Council Grant (BB/1008004/1) and Genesis Research Trust.

\section{References}

1. Ferre, S., Casado, V., Devi, L. A., Filizola, M., Jockers, R., Lohse, M. J., Milligan, G., Pin, J. P., and Guitart, X. (2014) G protein-coupled receptor oligomerization revisited: functional and pharmacological perspectives. Pharmacological reviews 66, 413-434

2. Gomes, I., Ayoub, M. A., Fujita, W., Jaeger, W. C., Pfleger, K. D., and Devi, L. A. (2016) G Protein-Coupled Receptor Heteromers. Annu Rev Pharmacol Toxicol 56, 403-425 
3. Kenakin, T., Agnati, L. F., Caron, M., Fredholm, B., Guidoli, D., Kobilka, B., Lefkowitz, R. W., Lohse, M., Woods, A., and Fuxe, K. (2010) International Workshop at the Nobel Forum, Karolinska Institutet on $\mathrm{G}$ protein-coupled receptors: finding the words to describe monomers, oligomers, and their molecular mechanisms and defining their meaning. Can a consensus be reached? J Recept Signal Transduct Res 30, 284-286

4. Angers, S., Salahpour, A., Joly, E., Hilairet, S., Chelsky, D., Dennis, M., and Bouvier, M. (2000) Detection of beta 2-adrenergic receptor dimerization in living cells using bioluminescence resonance energy transfer (BRET). Proceedings of the National Academy of Sciences of the United States of America 97, 3684-3689

5. Hounsou, C., Margathe, J. F., Oueslati, N., Belhocine, A., Dupuis, E., Thomas, C., Mann, A., Ilien, B., Rognan, D., Trinquet, E., Hibert, M., Pin, J. P., Bonnet, D., and Durroux, T. (2015) Time-resolved FRET binding assay to investigate hetero-oligomer binding properties: proof of concept with dopamine D1/D3 heterodimer. ACS Chem Biol 10, 466-474

6. Albizu, L., Cottet, M., Kralikova, M., Stoev, S., Seyer, R., Brabet, I., Roux, T., Bazin, H., Bourrier, E., Lamarque, L., Breton, C., Rives, M. L., Newman, A., Javitch, J., Trinquet, E., Manning, M., Pin, J. P., Mouillac, B., and Durroux, T. (2010) Time-resolved FRET between GPCR ligands reveals oligomers in native tissues. Nature chemical biology 6, 587-594

7. Pfleger, K. D., Dalrymple, M. B., Dromey, J. R., and Eidne, K. A. (2007) Monitoring interactions between G-protein-coupled receptors and betaarrestins. Biochemical Society transactions 35, 764-766

8. Ramsay, D., Kellett, E., McVey, M., Rees, S., and Milligan, G. (2002) Homoand hetero-oligomeric interactions between G-protein-coupled receptors in living cells monitored by two variants of bioluminescence resonance energy transfer (BRET): hetero-oligomers between receptor subtypes form more efficiently than between less closely related sequences. The Biochemical journal 365, 429-440

9. Mazurkiewicz, J. E., Herrick-Davis, K., Barroso, M., Ulloa-Aguirre, A., LindauShepard, B., Thomas, R. M., and Dias, J. A. (2015) Single-molecule analyses of fully functional fluorescent protein-tagged follitropin receptor reveal homodimerization and specific heterodimerization with lutropin receptor. Biology of reproduction 92, 100

10. Zakrys, L., Ward, R. J., Pediani, J. D., Godin, A. G., Graham, G. J., and Milligan, G. (2014) Roundabout 1 exists predominantly as a basal dimeric complex and this is unaffected by binding of the ligand Slit2. The Biochemical journal 461, 61-73

11. Kasai, R. S., Suzuki, K. G., Prossnitz, E. R., Koyama-Honda, I., Nakada, C., Fujiwara, T. K., and Kusumi, A. (2011) Full characterization of GPCR monomer-dimer dynamic equilibrium by single molecule imaging. The Journal of cell biology 192, 463-480

12. Hern, J. A., Baig, A. H., Mashanov, G. I., Birdsall, B., Corrie, J. E., Lazareno, S., Molloy, J. E., and Birdsall, N. J. (2010) Formation and dissociation of M1 muscarinic receptor dimers seen by total internal reflection fluorescence 
imaging of single molecules. Proceedings of the National Academy of Sciences of the United States of America 107, 2693-2698

13. Calebiro, D., Rieken, F., Wagner, J., Sungkaworn, T., Zabel, U., Borzi, A., Cocucci, E., Zurn, A., and Lohse, M. J. (2013) Single-molecule analysis of fluorescently labeled G-protein-coupled receptors reveals complexes with distinct dynamics and organization. Proceedings of the National Academy of Sciences of the United States of America 110, 743-748

14. Scarselli, M., Annibale, P., and Radenovic, A. (2012) Cell type-specific beta2adrenergic receptor clusters identified using photoactivated localization microscopy are not lipid raft related, but depend on actin cytoskeleton integrity. The Journal of biological chemistry 287, 16768-16780

15. Jonas, K. C., Fanelli, F., Huhtaniemi, I. T., and Hanyaloglu, A. C. (2015) Single molecule analysis of functionally asymmetric $G$ protein-coupled receptor (GPCR) oligomers reveals diverse spatial and structural assemblies. The Journal of biological chemistry 290, 3875-3892

16. Gonzalez, S., Moreno-Delgado, D., Moreno, E., Perez-Capote, K., Franco, R., Mallol, J., Cortes, A., Casado, V., Lluis, C., Ortiz, J., Ferre, S., Canela, E., and McCormick, P. J. (2012) Circadian-related heteromerization of adrenergic and dopamine $\mathrm{D}(4)$ receptors modulates melatonin synthesis and release in the pineal gland. PLoS Biol 10, e1001347

17. Nelson G, Hoon MA, Chandrashekar J, Zhang Y, Ryba NJ, Zuker CS. (2001) Mammalian sweet taste receptors. Cell. 106(3):381-90

18. Nelson G, Chandrashekar J, Hoon MA, Feng L, Zhao G, Ryba NJ, Zuker CS (2002) An amino-acid taste receptor. Nature 416(6877):199-202

19. Xu H, Staszewski L, Tang H, Adler E, Zoller M, Li X. (2004) Different functional roles of T1R subunits in the heteromeric taste receptors. Proc Natl Acad Sci U S A. 101(39):14258-63

20. Kaupmann, K., Malitschek, B., Schuler, V., Heid, J., Froestl, W., Beck, P., Mosbacher, J., Bischoff, S., Kulik, A., Shigemoto, R., Karschin, A., and Bettler, B. (1998) GABA(B)-receptor subtypes assemble into functional heteromeric complexes. Nature 396, 683-687

21. Duthey B, Caudron S, Perroy J, Bettler B, Fagni L, Pin JP, Prézeau L. (2001) A single subunit (GB2) is required for G-protein activation by the heterodimeric GABA(B) receptor. J. Biol. Chem. 277(5):3236-41

22. Pin JP, Kniazeff J, Binet V, Liu J, Maurel D, Galvez T, Duthey B, Havlickova M, Blahos J, Prézeau L, Rondard P. (2004) Activation mechanism of the heterodimeric GABA(B) receptor. Biochem Pharmacol. 68(8):1565-72

23. Wellman M, Abizaid A. (2015) Growth Hormone Secretagogue Receptor Dimers: A New Pharmacological Target(1,2,3). eNeuro.2(2). pii:

24. Yin Y, Li Y, Zhang W. (2014) The growth hormone secretagogue receptor: its intracellular signaling and regulation. Int J Mol Sci. 15(3):4837-55 
25. Rediger A, Tarnow $P$, Bickenbach A, Schaefer M, Krude H, Gruters A, Biebermann H (2009) Heterodimerization of hypothalamic G-protein-coupled receptors involved in weight regulation. Obes Facts. 2(2):80-6

26. Rediger A, Piechowski CL, Yi CX, Tarnow P, Strotmann R, Grüters A, Krude $H$, Schöneberg T, Tschöp MH, Kleinau G, Biebermann H (2011) Mutually opposite signal modulation by hypothalamic heterodimerization of ghrelin and melanocortin-3 receptors. J Biol Chem. 286(45):39623-31

27. Schelshorn D, Joly F, Mutel S, Hampe C, Breton B, Mutel V, Lütjens R. (2012) Lateral allosterism in the glucagon receptor family: glucagon-like peptide 1 induces G-protein-coupled receptor heteromer formation. Mol Pharmacol. 81(3):309-18

28. Hauge M, Ekberg JP, Engelstoft MS, Timshel P, Madsen AN, Schwartz TW (2016) Gq and Gs signaling acting in synergy to control GLP-1 secretion. Mol Cell Endocrinol. pii: S0303-7207(16)30493-2

29. Hauge M, Vestmar MA, Husted AS, Ekberg JP, Wright MJ, Di Salvo J, Weinglass AB, Engelstoft MS, Madsen AN, Lückmann M, Miller MW, Trujillo ME, Frimurer TM, Holst B, Howard AD, Schwartz TW. (2014) GPR40 (FFAR1) - Combined $\mathrm{Gs}$ and $\mathrm{Gq}$ signaling in vitro is associated with robust incretin secretagogue action ex vivo and in vivo. Mol Metab. 4(1):3-14.

30. Murat B, Devost D, Andrés M, Mion J, Boulay V, Corbani M, Zingg $\mathrm{HH}$, Guillon G (2012) V1b and CRHR1 receptor heterodimerization mediates synergistic biological actions of vasopressin and $\mathrm{CRH}$. Mol Endocrinol. 26(3):502-20

31. Jonas KC, Oduwole OO, Peltoketo H, Rulli SB, Huhtaniemi IT (2014) Mouse models of altered gonadotrophin action: insight into male reproductive disorders. Reproduction. 48(4):R63-70

32. Peltoketo H, Rivero-Müller A, Ahtiainen P, Poutanen M, Huhtaniemi (2010) Consequences of genetic manipulations of gonadotrophins and gonadotrophin receptors in mice. Ann Endocrinol (Paris). 71(3):170-6

33. Rivero-Müller A, Chou YY, Ji I, Lajic S, Hanyaloglu AC, Jonas K, Rahman N, $\mathrm{Ji} \mathrm{TH}$, Huhtaniemi I (2010) Rescue of defective G protein-coupled receptor function in vivo by intermolecular cooperation. Proc Natl Acad Sci U S A. 107(5):2319-24

34. Guan R, Wu X, Feng X, Zhang M, Hébert TE, Segaloff DL (2010) Structural determinants underlying constitutive dimerization of unoccupied human follitropin receptors. Cell Signal. 22(2):247-56

35. Guan R, Feng X, Wu X, Zhang M, Zhang X, Hébert TE, Segaloff DL (2009) Bioluminescence resonance energy transfer studies reveal constitutive dimerization of the human lutropin receptor and a lack of correlation between receptor activation and the propensity for dimerization. $J$ Biol Chem. 284(12):7483-94

36. Urizar E, Montanelli L, Loy T, Bonomi M, Swillens S, Gales C, Bouvier M, Smits G, Vassart G, Costagliola S. (2005) Glycoprotein hormone receptors: 
link between receptor homodimerization and negative cooperativity. EMBO J. 24(11):1954-64.

37. Tao YX, Johnson NB, Segaloff DL (2004) Constitutive and agonist-dependent self-association of the cell surface human lutropin receptor. $J$ Biol Chem. 279(7):5904-14

38. Horvat RD, Barisas BG, Roess DA (2001) Luteinizing hormone receptors are self-associated in slowly diffusing complexes during receptor desensitization. Mol Endocrinol. 5(4):534-42.

39. Mazurkiewicz JE, Herrick-Davis K, Barroso M, Ulloa-Aguirre A, LindauShepard B, Thomas RM, Dias JA. (2015) Single-molecule analyses of fully functional fluorescent protein-tagged follitropin receptor reveal homodimerization and specific heterodimerization with lutropin receptor. Biol Reprod. 92(4):100

40. Feng X, Zhang M, Guan R, Segaloff DL (2013) Heterodimerization between the lutropin and follitropin receptors is associated with an attenuation of hormone-dependent signaling. Endocrinology. 154(10):3925-30

41. Jeppesen JV, Kristensen SG, Nielsen ME, Humaidan P, Dal Canto M, Fadini R, Schmidt KT, Ernst E, Yding Andersen C (2012) LH-receptor gene expression in human granulosa and cumulus cells from antral and preovulatory follicles. J Clin Endocrinol Metab. 97(8):E1524-31

42. Casarini L, Riccetti L, De Pascali F, Nicoli A, Tagliavini S, Trenti T, La Sala GB, Simoni M. (2016) Follicle-stimulating hormone potentiates the steroidogenic activity of chorionic gonadotropin and the anti-apoptotic activity of luteinizing hormone in human granulosa-lutein cells in vitro. Mol Cell Endocrinol. 422:103-14

43. González S, Moreno-Delgado D, Moreno E, Pérez-Capote K, Franco R, Mallol J, Cortés A, Casadó V, Lluís C, Ortiz J, Ferré S, Canela E, McCormick PJ. (2012) Circadian-related heteromerization of adrenergic and dopamine $D_{4}$ receptors modulates melatonin synthesis and release in the pineal gland. PLOS Biol. 10(6):e1001347

44. Kern A, Albarran-Zeckler R, Walsh HE, Smith RG. (2012) Apo-ghrelin receptor forms heteromers with DRD2 in hypothalamic neurons and is essential for anorexigenic effects of DRD2 agonism. Neuron. 73(2):317-32

45. Park S, Jiang $\mathrm{H}$, Zhang $\mathrm{H}$, Smith RG (2012) Modification of ghrelin receptor signaling by somatostatin receptor-5 regulates insulin release. Proc Natl Acad Sci U S A. 109(46):19003-8

46. Müller TD, Müller A, Yi CX, Habegger KM, Meyer CW, Gaylinn BD, Finan B, Heppner K, Trivedi C, Bielohuby M, Abplanalp W, Meyer F, Piechowski CL, Pratzka J, Stemmer K, Holland J, Hembree J, Bhardwaj N, Raver C, Ottaway N, Krishna R, Sah R, Sallee FR, Woods SC, Perez-Tilve D, Bidlingmaier M, Thorner MO, Krude H, Smiley D, DiMarchi R, Hofmann S, Pfluger PT, Kleinau G, Biebermann H, Tschöp MH. (2013) The orphan receptor Gpr83 regulates systemic energy metabolism via ghrelin-dependent and ghrelin-independent mechanisms. Nat Commun. 4:1968 
47. S. AbdAlla, H. Lother, A. el Massiery, U. Quitterer (2001) Increased AT(1) receptor heterodimers in preeclampsia mediate enhanced angiotensin II responsiveness Nat Med, $7: 1003-1009$

48. U. Quitterer, H. Lother, S. AbdAlla (2004) AT1 receptor heterodimers and angiotensin II responsiveness in preeclampsia Semin Nephrol, 24: 115-119

49. Guidolin D, Agnati LF, Marcoli M, Borroto-Escuela DO, Fuxe K. (2015) Gprotein-coupled receptor type $A$ heteromers as an emerging therapeutic target. Expert Opin Ther Targets. 19(2):265-83

50. Gomes I, Fujita W, Gupta A, Saldanha SA, Negri A, Pinello CE, Eberhart C, Roberts E, Filizola M, Hodder P, Devi LA. (2013) Identification of a $\mu-\delta$ opioid receptor heteromer-biased agonist with antinociceptive activity. Proc Natl Acad Sci U S A. 110(29):12072-7

51. Berque-Bestel $I^{1}$, Lezoualc'h F, Jockers R (2008) Bivalent ligands as specific pharmacological tools for $G$ protein-coupled receptor dimers Curr Drug Discov Technol. 5(4):312-8.

52. Akgün $E^{1}$, Javed MI, Lunzer MM, Smeester BA, Beitz AJ, Portoghese PS. (2013) Ligands that interact with putative MOR-mGluR5 heteromer in mice with inflammatory pain produce potent antinociception. Proc Natl Acad Sci U SA. 110(28):11595-9

53. Colao A, Filippella M, Pivonello R, Di Somma C, Faggiano A, Lombardi G.(2007) Combined therapy of somatostatin analogues and dopamine agonists in the treatment of pituitary tumours. Eur $J$ Endocrinol. 156 Suppl $1:$ S57-63

54. Rocheville $\mathrm{M}^{1}$, Lange DC, Kumar U, Patel SC, Patel RC, Patel YC (2000) Receptors for dopamine and somatostatin: formation of hetero-oligomers with enhanced functional activity. Science. 288(5463):154-7

55. Jaquet P, Gunz G, Saveanu A, Dufour H, Taylor J, Dong J, Kim S, Moreau JP, Enjalbert A, Culler MD (2005) Efficacy of chimeric molecules directed towards multiple somatostatin and dopamine receptors on inhibition of $\mathbf{G H}$ and prolactin secretion from $\mathrm{GH}$-secreting pituitary adenomas classified as partially responsive to somatostatin analog therapy. Eur $J$ Endocrinol. 53(1):135-41.

56. Jaquet $P$, Gunz G, Saveanu A, Barlier A, Dufour H, Taylor J, Dong J, Kim S, Moreau JP, Culler MD (2005) BIM-23A760, a chimeric molecule directed towards somatostatin and dopamine receptors, vs universal somatostatin receptors ligands in $\mathrm{GH}$-secreting pituitary adenomas partial responders to octreotide. J Endocrinol Invest. 28(11 Suppl International):21-7.

57. Bonger KM, van den Berg RJ, Knijnenburg AD, Heitman LH, van Koppen CJ, Timmers CM, Overkleeft HS, van der Marel GA (2009) Discovery of selective luteinizing hormone receptor agonists using the bivalent ligand method ChemMedChem.4(7):1189-95

58. Bonger KM, Hoogendoorn S, van Koppen CJ, Timmers CM, van der Marel GA, Overkleeft HS (2010) Development of Selective LH Receptor Agonists by Heterodimerization with a FSH Receptor Antagonist. ACS Med Chem Lett. 8;2(1):85-9. 
59. Ayoub MA, Zhang Y, Kelly RS, See HB, Johnstone EK, McCall EA, Williams $\mathrm{JH}$, Kelly DJ, Pfleger KD (2015) Functional interaction between angiotensin II receptor type 1 and chemokine (C-C motif) receptor 2 with implications for chronic kidney disease. PLOS ONE 10(3): e0119803

60. Agnes RS, Lee YS, Davis P, Ma SW, Badghisi H, Porreca F, Lai J, Hruby VJ.(2006) Structure-activity relationships of bifunctional peptides based on overlapping pharmacophores at opioid and cholecystokinin receptors. J Med Chem. 49(10):2868-75

62. Yamamoto T, Nair P, Jacobsen NE, Davis P, Ma SW, Navratilova E, Moye S, Lai J, Yamamura HI, Vanderah TW, Porreca F, Hruby VJ (2008) The importance of micelle-bound states for the bioactivities of bifunctional peptide derivatives for delta/mu opioid receptor agonists and neurokinin 1 receptor antagonists. J Med Chem.51(20):6334-47

63. Largent-Milnes TM, Brookshire SW, Skinner DP Jr, Hanlon KE, Giuvelis D, Yamamoto T, Davis P, Campos CR, Nair P, Deekonda S, Bilsky EJ, Porreca F, Hruby VJ, Vanderah TW. (2013) Building a better analgesic: multifunctional compounds that address injury-induced pathology to enhance analgesic efficacy while eliminating unwanted side effects. J Pharmacol Exp Ther. 347(1):7-19.

64. Casadó V, Cortés A, Mallol J, Pérez-Capote K, Ferré S, Lluis C, Franco R, Canela El. (2009) GPCR homomers and heteromers: a better choice as targets for drug development than GPCR monomers? Pharmacol Ther. 124(2):248-57

65. Sohy D, Yano H, de Nadai P, Urizar E, Guillabert A, Javitch JA, Parmentier M, Springael JY.(2009) Hetero-oligomerization of CCR2, CCR5, and CXCR4 and the protean effects of "selective" antagonists. J Biol Chem. 284(45):31270-9

66. Geng Y, Mosyak L, Kurinov I, Zuo H, Sturchler E, Cheng TC, Subramanyam $P$, Brown AP, Brennan SC, Mun HC, Bush M, Chen Y, Nguyen TX, Cao B, Chang DD, Quick M, Conigrave AD, Colecraft HM, McDonald P, Fan QR. (2016) Structural mechanism of ligand activation in human calcium-sensing receptor. Elife. 19;5. pii: e13662

67. Fotiadis D, Jastrzebska B, Philippsen A, Müller DJ, Palczewski K, Engel A. (2006) Structure of the rhodopsin dimer: a working model for G-proteincoupled receptors. Curr Opin Struct Biol.16(2):252-9

68 Huang J, Chen S, Zhang JJ, Huang XY (2013) Crystal structure of oligomeric $\beta 1$-adrenergic $G$ protein-coupled receptors in ligand-free basal state. Nat Struct Mol Biol. 20(4):419-25

69 Miao Y, McCammon JA. (2016) Graded activation and free energy landscapes of a muscarinic G-protein-coupled receptor. Proc Natl Acad Sci U S A. 113(43):12162-12167

70. Staus DP, Strachan RT, Manglik A, Pani B, Kahsai AW, Kim TH, Wingler LM, Ahn S, Chatterjee A, Masoudi A, Kruse AC, Pardon E, Steyaert J, Weis WI, Prosser RS, Kobilka BK, Costa T, Lefkowitz RJ. (2016) Allosteric nanobodies reveal the dynamic range and diverse mechanisms of G-protein-coupled receptor activation. Nature. 535(7612):448-52 
71. DeVree BT, Mahoney JP, Vélez-Ruiz GA, Rasmussen SG, Kuszak AJ, Edwald E, Fung JJ, Manglik A, Masureel M, Du Y, Matt RA, Pardon E, Steyaert J, Kobilka BK, Sunahara RK. (2016) Allosteric coupling from G protein to the agonist-binding pocket in GPCRs. Nature. 535 (7610):182-6.

72. Ring AM, Manglik A, Kruse AC, Enos MD, Weis WI, Garcia KC, Kobilka BK. (2013) Adrenaline-activated structure of $\beta 2$-adrenoceptor stabilized by an engineered nanobody. Nature. 502 (7472):575-9

73. Maussang D, Mujić-Delić A, Descamps FJ, Stortelers C, Vanlandschoot $P$, Stigter-van Walsum M, Vischer HF, van Roy M, Vosjan M, Gonzalez-Pajuelo M, van Dongen GA, Merchiers P, van Rompaey P, Smit MJ. (2013) Llamaderived single variable domains (nanobodies) directed against chemokine receptor CXCR7 reduce head and neck cancer cell growth in vivo. J Biol Chem. 288(41):29562-72

74. Nygaard R, Zou Y, Dror RO, Mildorf TJ, Arlow DH, Manglik A, Pan AC, Liu CW, Fung JJ, Bokoch MP, Thian FS, Kobilka TS, Shaw DE, Mueller L, Prosser RS, Kobilka BK. (2013) The dynamic process of $\beta(2)$-adrenergic receptor activation. Cell. 152(3):532-42

75. Irannejad R, Tomshine JC, Tomshine JR, Chevalier M, Mahoney JP, Steyaert J, Rasmussen SG, Sunahara RK, El-Samad H, Huang B, von Zastrow M. (2013) Conformational biosensors reveal GPCR signalling from endosomes. Nature 495(7442):534-8

76. Rasmussen SG, Choi HJ, Fung JJ, Pardon E, Casarosa P, Chae PS, Devree BT, Rosenbaum DM, Thian FS, Kobilka TS, Schnapp A, Konetzki I, Sunahara RK, Gellman SH, Pautsch A, Steyaert J, Weis WI, Kobilka BK. (2011) Structure of a nanobody-stabilized active state of the $\beta(2)$ adrenoceptor. Nature. 469(7329):175-80.

77. Gomes I, Gupta A, Bushlin I, Devi LA. (2014) Antibodies to probe endogenous $\mathrm{G}$ protein-coupled receptor heteromer expression, regulation, and function. Front Pharmacol. 3;5:268 
Highlights (for review)

\section{Highlights}

- Homo/heteromerization can diversify GPCR function

- This article explores the in vitro and in vivo significance of GPCR heteromers, with focus on endocrine-related processes

- This article describes the current outlook for pharmacological interventions and current/future treatment paradigms for GPCR heteromers. 


\begin{tabular}{|c|c|c|}
\hline GPCR Heteromer & Endocrine system/axis & References \\
\hline GHSR/MC3R & Hypothalamic-gastrointestinal axis & 25,26 \\
\hline GHSR/D2R & Hypothalamic-gastrointestinal axis & 44 \\
\hline GHSR/GPR83 & Hypothalamic nuclei-metabolism & 46 \\
\hline GHSR/SST5a & Insulinotropic action in pancreas & 45 \\
\hline GLP-1R/GIPR & Insulinotropic action in pancreas & 27 \\
\hline LHR/FSHR & $\begin{array}{l}\text { Hypothalamic-pituitary-ovarian axis/ pre-ovulatory } \\
\text { ovarian follicle }\end{array}$ & 39,40 \\
\hline D4R/ $\alpha 1 B R$ & Melatonin secretion from pineal gland & 43 \\
\hline D4R/ß1R & Melatonin secretion from pineal gland & 43 \\
\hline AT1R/B2R & $\begin{array}{l}\text { Renin-angiotensin system in blood pressure } \\
\text { regulation }\end{array}$ & 47,48 \\
\hline V1bR/CRHR & $\begin{array}{l}\text { Hypothalamic-pituitary-adrenal axis/ adrenal } \\
\text { chromaffin cells }\end{array}$ & 30 \\
\hline D2R/SST2 & Growth hormone-secreting pituitary tumors & 53,54 \\
\hline
\end{tabular}

Table 1. Examples of $\mathrm{G}$ protein-coupled receptor (GPCR) heteromers that have been identified in distinct endocrine systems (see text). Abbreviations: $\alpha 1 \mathrm{~B}$ adrenergic receptors ( $\alpha$ 1BR); Angiotensin 1 receptor (AT1R); Beta1-adrenergic receptor $(\beta 1 \mathrm{R})$; Bradykinin 2 receptor (B2R); Corticotrophin releasing hormone receptor (CRHR); Dopamine D2 receptor (D2R); Dopamine D4 receptor (D4R); Follicle stimulating hormone receptor (FSHR); Gastricinhibitory polypeptide receptor (GIPR); Growth hormone secretagogue receptor (GHSR); Glucagon-like peptide-1 receptor (GLP-1R); G protein-receptor 83 (GPR83); Luteinizing hormone receptor (LHR); Melanocortin-3 receptor (MC3R); somatostatin receptor 2 (SST2); somatostatin receptor $5 \mathrm{a}$ (SST5a); Vasopressin $1 \mathrm{~b}$ receptor $(\mathrm{V} 1 \mathrm{bR})$ 